\title{
新时代背景下高职院校共青团干部专业能力和职业素养提升制 度研究
}

\author{
李志辉 \\ 苏州健雄职业技术学院 \\ DOI:10.32629/mef.v3i6.1648
}

\begin{abstract}
[摘 要] 习近平总书记强调, “要建设一支忠实贯彻新时代中国特色社会主义思想、符合新时期好干部 标准、忠诚、干净、担当、数量充足、充满活力的高素质专业化年轻干部队伍。”总书记对高校团干 部队伍提出了新的要求, 如何顺应时代要求, 建立高校团干部专业能力和职业素养的提升机制是高校 团组织亟待解决的重要问题。本文希望通过对高校团干部专业能力和职业素养的培训的剖析和研究, 找到新时代背景下的高校团干部专业能力和职业素养提升的可行性机制。
\end{abstract}

[关键词] 新时代; 团千部; 专业能力; 职业素养; 提升制度

中图分类号: G71 文献标识码: A

Research on the Professional Ability and Professional Quality Improvement System of the League Member Cadres in Higher Vocational Colleges under the Background of the New Era Zhihui Li

Suzhou Chien-Shiung Institute of Technology

[Abstract] General Secretary Xi Jinping emphasized that "It is necessary to build a team of high-quality professional young cadres who are loyal, clean, responsible, have sufficient numbers, and are full of vitality, meet the standards of good cadres in the new era, and faithfully implement the socialist ideology with Chinese characteristics in the new era." General Secretary Xi puts forward new requirements for the league cadres of colleges and universities. How to conform to the requirements of the times and establish a mechanism for improving the professional ability and professional quality of college league cadres is an important issue that needs to be solved urgently in the organization of college leagues. This article hopes to find the professional ability and professional quality of college league cadres in the background of the new era through the analysis and research on the training of the professional ability and professional quality of college league cadres.

[Key words] new area; league member cadres; professional ability; improvement system

高校团干部是当代大学生群体中的 佼佼者, 是高校团组织活动中的中坚力 量, 也是中国共产党的助手和后备军, 承担着服务学校工作、服务青年学生成 长等重要工作。高校团组织承担如此重 要的任务, 对选拔和使用年轻团干部提 出了更高的要求, 需要高校团干部符合 具备较高思想觉悟、专业能力、职业素 养等方面的标准。此外, 新时代诞生新 的历史使命, 需要高效团干部更新和提 升自己的专业能力和职业素养来完成团 组织交代的任务。
1 高校团干部专业能力和职业素养 提升制度研究必要性

\section{1 共青团基本任务的必要要求}

中国共产主义青年团在现阶段的基 本任务是: 坚定不移地贯彻党在社会主 义初级阶段的基本路线, 以经济建设为 中心, 坚持四项基本原则, 坚持改革开 放, 在建设中国特色社会主义的伟大实 践中, 造就有理想、有道德、有文化、 有纪律的接班人, 努力为党输送新鲜血 液, 为国家培养青年建设人才, 团结带 领广大青年, 自力更生, 艰苦创业, 积
极推动社会主义物质文明、政治文明和 精神文明建设, 为全面建设小康社会、 加快推进社会主义现代化贡献智慧和力 量。为完成现阶段共青团基本任务, 高 职院校团组织成员有必要时刻提升专业 能力和职业素养, 以期待尽早达到该任 务目标。

1. 2 推动高校学风建设的必要要求 高校团干部多数来自于各班级中的 积极分子, 这部分同学有着很好的群众 基础, 言行有着很好的示范作用。高校 团干部在开展工作的过程中, 需要和广 
大同学 “打成一片”, 在此过程中, 团干 部能够展现出很好的专业能力和职业素 养，对广大同学有着很好的示范和带动 作用。特别是在高校的学风建设领域, 团干部的示范和引领作用不可或缺，不 论是在第一课堂, 还是第二课堂方面, 团干部在优秀学风领域的良好示范, 都 能够对其他同学产生很好的带动作用。 反而言之, 如果高校团干部在学习上, 起不到很好的榜样作用, 甚至是负面示 范, 由于团干部在普通同学心目中有一 定威信, 并起到带头作用, 其他同学必 定效仿之。

\section{3 完成新时代下使命的必要要求}

有学者认为: 高校团干部创新能力 与日益变化的国际国内形势不完全适 应; 宣传动员能力与信息交融的社会特 点不完全适应; 服务能力与当前 大学生 思维日益活跃及多元化需求不适应。具 体表现在：高校团干部工作思路陈旧， 创新能力不足; 少数团干部政治觉悟较 低, 且不愿意积极主动学习党的先进理 论和最新政策等。此外, 经济在发展, 社会在进步，每天都有新的事物出现， 新的矛盾也会浮现。在社会经济机构深 度变革、青年学生价值观多元化的今天， 高校团干部作为共青团事业发展的中坚 力量, 需要不断更新迭代自己的专业能 力和职业素养，以适应新时代下对高校 团干部的要求, 逐步完善新时代背景下 解决新的矛盾的能力和素质。

\section{2 高职院校共青团干部专业能 力和职业素养提升策略}

高校团干部作为教师和学生的桥 梁, 起着承上启下的作用。同时, 作为 高校日常学生工作的管理者和执行者, 对广大学生群体影响作用巨大。在团干 部任用过程中, 应关注该部分群体的专 业能力和职业素养的提升, 以便更好的 发挥高校团干部在高校学生工作管理工 作中的作用。一味原地踏步, 止步不前, 有着被社会淘汰的风险。

2.1 优化选拔制度，提升共青团鬼 力, 激发进步内驱力

目前, 各大高校对于共青团组织的 重视程度不一, 资源配备程度也不一样。
如此情况, 导致诸多高校共青团发展思 路混乱, 没有明晰的路径和目标, 选拔 制度也缺乏弹性, 若干年一成不变, 不 符合新时代下发展的需求。各大高校应 优化选拔制度, 采取民主与集中相结合 的选举方式, 并合理安排民主与集中的 权重, 保证学生参与积极性的同时, 又 能选举出合格的团干部。在确定好 “选 拔” 制度之后, 还需要优化 “退出” 机 制, 现阶段对数共青团组织没有明确的 退出机制, 导致诸多团员进入后并认为 一劳永逸, 不再追求进步。缺乏合理 “退 出” 机制, 必将折损共青团鬼米力, 也无 法鞭策和激励共青团成员积极进取, 勇 为人先, 优胜劣汰, 保证共青团队伍的 优良属性, 提升其魅力, 成为大学生需 要 “攀登” 的存在。那么, 身处共青团 队伍中的同学, 便会产生追求进步的内 驱力。

2. 2 围绕基本任务, 全过程培养, 紧 扣时代脉搏

各大高校能够做到对共青团任务认 识清晰, 但是团干部开展工作的过程中, 容易产生偏差。现阶段, 多数高校团干 部的主要工作依然是协助班主任、辅导 员及相关部分完成各种事务性工作，没 有很好的抓住共青团任务和使命开展工 作。这种工作模式, 是认知的偏差, 无 法完成新时代交给共青团的任务, 也将 严重削弱团干部的创新能力、想象力, 打击其工作的积极性和主观能动性。通 常, 各大高校对新选拔的团干部会进行 岗前培训, 指导其培养作为团干部应该 具备的职业素养和能力, 认清共青团的 本质。但在随后的共青团工作中, 多数 处于放任自流、自生自灭的状态之中, 鲜有根据时代发展产生的新需求对团干 部进行针对性的培训, 导致多数团干部 职业素养和专业能力止步不前, 处于原 地踏步的状态。所以, 各高校对于团干 部应该制定严格的围绕共青团任务和使 命的培训计划, 分阶段执行, 保证团干 部专业能力和职业素养的定期更新, 跟 上时代发展步伐。

2. 3优化团干部监督和约束机制, 长 期执行
高校团干部是学生, 是一群处于人 生观、世界观、价值观正在养成阶段的 年轻人。引起该群体树立正确的人生观、 世界观、价值观, 需要在其成长阶段予 以指导的同时, 还需要对其进行监督和 约束, 放弃其 “跑偏”。现阶段, 多数高 校对于团干部的监督和约束的文件, 长 期束之高阁, 很难长期有效的执行。在 团干部开展工作过程中, 组织应该监督 和考察其开展工作的初衷和目的, 是否 包含太多的功利性意识。对于这种, 应 该予以即时纠正, 甚至是 “剔除” 出队 伍。如若不然, 荒废了该学生的同时, 其他团干部也会效仿, 无法调动共青团 队伍的积极性和奉献意识。长此以往, 必将对团组织形象、战斗力造成极大的 负面影响。

2. 4确保 “入口” 和 “出口” 常开门, 动态更新队伍

对于组织而言, 没有定期的流动和 更新, 犹如一潭死水, 是没有活力的。 只有让组织保持通畅的 “进出” 通道, 才能像活水一样, 流淌不歇, 直到永远。 共青团队伍要保持通畅的 “进出” 通道, 进是指对于符合团干部要求的团员要积 极予以肯定并提拔，对于符合团员标准 的同学, 要积极吸收其加入团组织。及 时 “添油加气”, 输入新鲜血液, 才能保 持组织的活力, 在组织内部形成良性竞 争。出是两个通道, 一是, 对于优秀的 团干部, 要积极予以培养, 争取让其早 日加入党组织, 成为中国共产党的一员, 为党的事业添砖加瓦; 二是对于表现不 佳, 不符合团干部要求的, 及时予以辞 退, 让其从团员阶段重新做起, 当然也 不排除，对于连团员标准都不符合的同 学, 可以考虑 “剔除” 出团组织。如此 “进出”, 基本能够保证让有能力, 有理 想, 有抱负的同学留在组织中, 做出自 己应该有的贡献，同时，也让共青团成 为大家向往的组织。

团干部的培养是一个长期且动态的 过程。长期, 是因为共青团组织要为我 国实现共产主义而长期奋斗; 动态, 是 因为新时代对共青团产生新的要求。各 大高校在共青团干部培养过程中，会遇 


\title{
基于现代学徒制的高职院校学生工匠精神培养研究 ---以政府采购管理专业为例
}

\author{
钱书成 \\ 东莞职业技术学院 \\ DOI:10.32629/mef.v3i6.1631
}

\begin{abstract}
[摘 要] 政府采购管理专业作为近几年高职院校教育的热门专业之一, 如何将现代学徒制的理念融入 到高职政府采购管理专业建设中去, 凸显这一专业教育中的 “工匠精神”, 强化这一专业教育的效果一 直是最近几年备受高职教育工作者们关注的焦点问题。所以, 本文从现代学徒制的内涵出发, 以政府 采购管理专业为例思考未来高职院校这一专业人才 “工匠精神” 培养的举措, 希望能对后续课程的展
\end{abstract} 开予以帮助。

[关键词] 现代学徒制; 高职院校; 工匠精神; 政府采购管理

中图分类号：G658.3 文献标识码：A

\section{Research on the Cultivation of Craftsman Spirit of Vocational College Students Based on Modern Apprenticeship \\ - Take Government Procurement Management as an Example Shucheng Qian \\ Dongguan Polytechnic}

[Abstract] It has been the focus of attention of higher vocational educators in recent years on how to integrate the concept of modern apprenticeship into the construction of the higher vocational government procurement management major, which is one of the most popular majors in higher vocational education in recent years, highlight the "craftsman spirit" in this professional education, and Strengthening the effect of this professional education. Therefore, starting from the connotation of modern apprenticeship, this article takes the government procurement management major as an example to think about the measures to cultivate the "craftsman spirit" of this professional talent in higher vocational colleges in the future, hoping to help the follow-up courses.

[Key words] modern apprenticeship; vocational college; craftsman spirit; government procurement management

随着我国高职教育改革的推进, 高 职院校作为我国专业技能人才培养的 “摇篮”, 越来越多的企业、事业单位意
识到高职专业人员培养对其企业、单位 人力资源储备的积极影响。尤其是近几 年, 随着高职院校与企业、事业单位沟
通、协作的逐步深入，定向人才培养也 日益成为了未来高职院校人员培育的发 展方向, 贴合企业、事业单位需求, 为
到各种问题, 但只要本着长期且动态的 原则，不断更新培养机制，定能培养出 符合时代要求的团干部。

\section{基金项目:}

2019年度江苏高校共青团思想政治 引领工作专项研究课题立项课题：新时 代背景下高职院校共青团干部专业能力 和职业素养提升策略研究(棵题编号:
LX2019097)。

[参考文献]

[1]近平.决胜全面建成小康社会, 夺取新时代中国特色社会主义伟大胜利 一中国共产党第十九次全国代表大会上 的报告[Z].北京: 人民出版社,2017:36

[2]慎之,等.译.本・阿格尔.西方马克 思主义概论 [M]. 北京: 中国人民大学出版
社,1991: 493.

[3]朱旭.新时期高校团学工作 模式创新研究 [J]. 文化创新比较研 究,2018(34):17-18.

作者简介：

李志辉 ( 1984-- ), 男, 汉族, 江 苏邳州人, 讲师, 硕士, 研究方向: 学 生管理。 